will be diminished by the examination of the preceding examples.

(2) That the work necessary to sustain in high velocity the weights of an apparatus composed of planes and a motor may be produced by motors so light as those that have actually been constructed, provided that care is taken to conveniently direct the apparatus in free flight; with other conclusions of an analogous character.

I hope soon to have the honour of submitting a more complete account of the experiments to the Academy.

\section{ON THE SOLID AND LIQUID PARTICLES} IN CLOUDS. ${ }^{1}$

$\mathrm{N}$ this paper are given the results of some observations made while on the Rigi in May last, on the solid and liquid particles in clouds. It was noticed, when making observations on the number of dust particles in the atmosphere, that when the top of the mountain was in cloud, the number of particles varied greatly in short intervals; while previous experience had shown that at elevated stations the number was fairly constant for long periods. In order to investigate the case of this want of uniformity in the impurity of clouded air, extreme conditions were selected, and the air tested in cloud and in the clear air outside of it. When this was done the clouded air was found to have always more dust in it than the air outside. Its humidity was of course also greater. The relative amount of dust in pure and in clouded air varied greatly. Some parts of the cloud had only about double the number of particles there were in the clear air, while in other parts the proportion was much greater. The best example tested occurred on the $25^{\text {th }}$ of the month, when there were observed 700 particles per c.c. in the clear air, while the number in cloud went up to over 3000 , and in one cloud to 4200 particles per c.c. These observations were taken on the top of the mountain while the clouds were passing over it; the readings being taken in the cloud and again when it had passed and was replaced by clear air.

These observations at once showed the cause of the variability in the number of dust-particles in the clouds. The dust acted as a kind of ear-mark, and showed that the air forming the clouds was impure valley air, which had forced its way up into the purer air above. This impure air had become more or less mixed with the purer upper air. Where little of the impure air had mixed with the upper air, the number of particles was not large, and the clouding slight; but where the valley air was greatly in excess, the number of particles was great, and the clouding dense. It should be noted here that all the clouds tested were cumulus. It is quite probable that the conditions in stratus and other clouds may be different.

During this visit to the Rigi there were a number of opportunities of investigating the water particles in clouds. The apparatus used was the small instrument described to the Society in May last. With this instrument the water particles in clouds can be easily seen, and the number falling on a given area counted. The results are similar to those already communicated to the Society from observations made in fogs during last winter. On observing with this instrument in clouds, the water particles were distinctly seen showering down, and the number falling on the micrometer easily counted. The number of drops falling was observed to vary greatly from time to time. At times so quickly did they fall that it was impossible to count the number that fell on only I sq. mm. The greatest rate actually counted was 60 drops per sq. $\mathrm{mm}$. in 30 seconds, but for a

' Abstract of Paper read before the Royal Society, Edinburgh, on July 6, by John Aitken, F.R.S. Communicated by permission of the Cuuncil of the Soc.ety.

NO. I I 34 , VOL. 44$]$ few seconds the rate was much quicker. Though the quick falls seldom lasted long, yet 30 drops per sq. $\mathrm{mm}$. per minute were frequently observed for a considerable time. The maximum rate of 60 per sq. $\mathrm{mm}$. per half minute gives 12,000 drops per square centimetre per minute, or 77,400 drops per square inch per minute. This does seem to be an enormous number of drops to fall on so small an area in the time. These drops, how ever, are so extremely small they rapidly evaporate, more than two or three being seldom visible at the same time on one square of the micrometer. The denser the cloud the quicker was the rate of fall, and as the cloud thinned away the drops fell at longer intervals, and they diminished in size at the same time.

It was frequently observed when the mountain-top was in clouds, particularly if they were not very dense overhead, that the surfaces of all exposed objects were quite dry; not only the stones on the ground, which might have received heat from the earth, but also wooden seats, posts, \&c., were all perfectly dry, and if wetted they soon dried. While everything was dry, the fog-counter showed that fine rain-drops were falling in immense numbers. From the fact that the air was packed full of these small drops of water, it might have been assumed that the air was saturated, and tests with properly-protected wet and dry bulb thermometers showed that it was saturated. A few observations were therefore made to explain this apparent contradiction of surfaces remaining dry while exposed to a continued shower of fine rain and surrounded by saturated air. The explanation was found to be, simply, radiant heat. Though the cloud may be so dense, it is impossible to see the sun or even a preponderance of light in one direction to indicate its position; yet, as a good deal of light penetrates under these conditions, it therefore seemed possible some heat might do so also. A thermometer with black bulb in vacuo showed that a considerable amount of heat penetrated the clouds under the conditions, as it rose $40^{\circ}$ to $50^{\circ}$ above the temperature of the air while the observations were being made. This radiant heat is absorbed by all exposed surfaces and heats them, while they in turn heat the air in contact with them, and the fine drops of water are either evaporated in this hot layer of air or after they come in contact with the heated surfaces. Other observations made on Pilatus pointed to the same conclusion. All large objects, such as seats, posts, \&c., were quite dry in cloud when there was any radiation; while small objects, such as pins, fine threads, \&c., were covered with beads of water. The large surfaces being more heated by radiation than small ones, when surrounded by air, these surfaces evaporate the drops falling on them, while the small ones, being kept cool by the passing air, are unable to keep tbemselves dry.

The observations made with the fog-counter point to the conclusion that the density or thickness of a cloud depends more on the number of water particles than on the number of dust particles in it. The number of the dust particles in the clouds varied too much and too quickly to enable any conclusion to be drawn from observations made in clouds themselves. However, on comparing the thickness of a cloud on the Rigi and a fog at low level, when the number of waterdrops was about the same, it is found that the fog, though thicker, was not greatly so, although there were only a few thousand dust-particles per c.c. in the cloud, while there were about 50,000 in the fog.

The observations with the fog-counter show that, whenever a cloud is formed, it at once begins to rain, and the small drops fall into the drier air underneath, where they are evaporated, the distance to which they will fall depending on their size and the dryness of the air. It is thought that much of the dissolving of clouds is brought about in this way. 